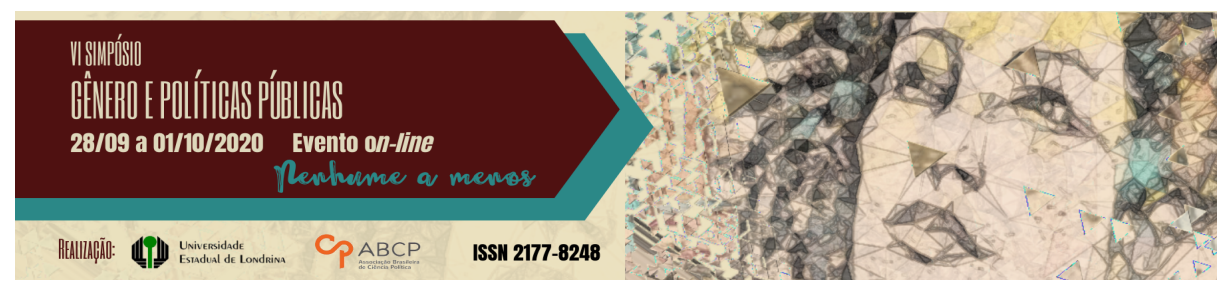

\title{
Dilemas teóricos da representação política de mulheres: pensando a igualdade representativa de gêneros como uma questão de justiça ${ }^{1}$
}

\author{
Madalena Gonçalves Castro²
}

\section{Resumo}

Em tempos de retrocessos democráticos - tendo em vista mulheres que defendem pautas conservadoras ligadas aos direitos sexuais e reprodutivos na esfera institucional brasileira - o presente trabalho visa abordar as potencialidades e os limites da inclusão de grupos minoritários nas instâncias de poder político que, por vezes, entra em conflito com o conteúdo substantivo da representação. A despeito das divergências entre mulheres eleitas, principalmente àquelas ligadas a esses direitos, argumento que reformas institucionais que busquem diminuir desigualdades de gênero na representação política devem ser defendidas não só em termos de igualdade política, mas também como uma questão de justiça. O objetivo principal é mostrar que a democratização da representação - no sentido de maior acesso à competição eleitoral e franqueamento de cargos políticos às minorias (aqui incluindo mulheres, negros, população indígena e LGBTQI+), é permeada por

1 Este trabalho é parte integrante de minha tese de doutorado, ainda em desenvolvimento, cujo objetivo é analisar as possibilidades de aproximação entre princípios normativos que norteiam teorias políticas feministas da representação e teorias liberais da justiça, de forma que sejam compatíveis com um ideal de representação justa, ou seja, que tenha em vista as desigualdades distributivas e simbólicas que permeiam as sociedades democráticas contemporâneas.

2 Doutoranda em Ciência Política do Instituto de Estudos Sociais e Políticos da Universidade do Estado do Rio de Janeiro (IESP-UERJ). Pesquisadora do NIMMIN (Núcleo Interdisciplinar de Mulheres, Movimentos, Instituições e Normatividades), da mesma instituição, e integrante da secretaria executiva da RedeGen (Rede Fluminense de Núcleos de pesquisa de Gênero, Sexualidade e Feminismos nas Ciências Sociais). Bolsista da Fundação de Amparo à Pesquisa do Estado do Rio de Janeiro (FAPERJ). O presente trabalho foi realizado com apoio da Coordenação de Aperfeiçoamento de Pessoal de Nível Superior - Brasil (CAPES) - Código de Financiamento 001.

E-mail: lena.mgc@gmail.com.

GT 13 - Gênero, participação e representação política 
diversos conflitos e não se traduz em uma coesão na defesa de pautas políticas de movimentos sociais ligados a esses grupos. Como objetivo secundário, busca-se apresentar uma argumentação normativa em prol da defesa de mais mulheres nas esferas de poder, em termos de igualdade política e independente do conteúdo substantivo da representação. O presente trabalho se baseia tanto em uma revisão bibliográfica de teorias da democracia, teorias feministas da representação política e teorias contemporâneas da justiça, quanto na análise de legislação eleitoral, dados e propostas recentes de reformas institucionais que versam sobre a disparidade na representação política de mulheres.

Palavras-chaves: democracia; representação política; igualdade de gênero; justiça.

\title{
Theoretical dilemmas of women's political representation: thinking of representative gender equality as a matter of justice
}

\begin{abstract}
In times of democratic setbacks - considering women who defend conservative agendas linked to sexual and reproductive rights in the Brazilian institutional sphere - the present work aims to address the potentialities and limits of the inclusion of minority groups in the instances of political power that, sometimes, enters in conflict with the substantive content of the representation. Despite the differences between elected women, especially those linked to these rights, I argue that institutional reforms that seek to reduce gender inequalities in political representation must be defended not only in terms of political equality, but also as a matter of justice. The main objective is to show that the democratization of representation - in the sense of greater access to electoral competition and the opening of political positions to minorities (here including women, blacks, indigenous people and LGBTQI +), is permeated by several conflicts and does not translate into a cohesion in the defense of political agendas of social movements linked to these groups. As a secondary objective, it seeks to present a normative argument for the defense of more women in the spheres of power, in terms of political equality and independent of the substantive content of representation. The present work is based both on a bibliographic review of theories of democracy, feminist theories of political representation and contemporary theories of justice, as well as on the analysis of electoral legislation, data and recent proposals for institutional reforms that address the disparity in the political representation of women.
\end{abstract}

Keywords: democracy; political representation; gender equality; justice. 
Não há como falar de representação política sem falar de democracia. Apesar de frequentemente aparecerem imbricados, a abordagem histórica de democracia e governo representativo os revela como conceitos que dizem respeito a coisas distintas. Originalmente contrária a ideia clássica de que todos os cidadãos se colocariam em praça pública como povo, soberano das decisões democráticas, a representação política surge pautada no princípio da distinção, segundo o qual, os eleitos seriam mais qualificados e superiores aos seus eleitores (MANIN, 2010). De maneira análoga e, consoante as análises de Ellen Wood (1995), as instituições representativas não teriam sido pensadas para ampliar a participação popular no governo frente a "impossibilidade da democracia direta em grandes Estados", mas ao contrário, para reduzí-la (MIGUEL, 2003, p. 130).

A despeito disso, nas democracias contemporâneas o ideal de participação política direta reaparece não apenas no sentido de que todos têm o direito de participar da vida pública, pressupondo uma igualdade política entre cidadãos, mas no de que o povo continua sendo o soberano das decisões tomadas pelos eleitos. O ideal de igualdade política também traz consigo a assunção de que diferentes interesses, ideias e perspectivas sociais deveriam estar igualmente representados nos arranjos institucionais. Indo de encontro ao princípio da distinção, ele continua sendo constantemente sustentado como resquício normativo da democracia ateniense e valor político central para a análise da qualidade das democracias. Nesse sentido,

escolher envolve necessariamente a comparação e a distinção. Os eleitos, os escolhidos, devem ter atributos que os demais não têm. Mas ao mesmo tempo, queremos votar naqueles com quem nos identificamos, que se não são iguais, pelo menos são parecidos conosco, têm os nossos atributos. Esses ideais são contraditórios. Há uma tensão interna entre eles (LIMONGI, 2015, p. 24). 
Como será visto adiante, essas discussões estão centradas em um tipo de representação que envolve a defesa de ideias e interesses comuns compartilhados pelos cidadãos. Nas democracias liberais, por sua vez, os novos Estados Nacionais não são homogêneos e o conflito político transparece sob uma ótica positiva, inerente à democracia. Além disso, o entendimento de bem público e do que deve ser valorizado pelos cidadãos como importante para a comunidade política na qual vivem, também se transforma e passa a se caracterizar pelas diferenças entre diversos grupos sociais, trazendo novas questões e problemas que a teoria democrática por si só, não resolve (DAHL, 2012, p. 45).

De uma maneira geral, as teorias da democracia se configuram como ideais normativos e guias de sistemas políticos ao redor do mundo. Embora a ideia de autogoverno e de repúdio à tirania seja constitutiva dessas teorias, seu conteúdo pode variar entre análises cujo caráter é essencialmente ético e àquelas que possuem um caráter essencialmente empírico ou descritivo. Nesse sentido, a democracia se apresenta tanto enquanto valor intrínseco quanto como um valor instrumental, que expressa uma outra dimensão dos compromissos assumidos nas sociedades democráticas.

A democracia tal qual analisada por Madison, enquanto líder político, e pelo teórico Schumpeter, autores frequentemente citados pelas teorias contemporâneas da democracia, pode ser descrita como inserida nesta segunda dimensão, uma vez que ela representa um método para que se atinja certos objetivos. Madison já via um potencial conflito entre os direitos das minorias e a formação de maiorias populares. Seus argumentos propugnavam não só a necessidade de separação de poderes, mas também um ideal de igualdade entre os cidadãos. O ideal de "uma pessoa, um voto", surge com o intuito de expressar igual consideração por todos os indivíduos e um compromisso que impede a formação de uma maioria que venha a decidir pela tirania, ou seja, pela supressão dos direitos naturais da minoria. Entretanto, embora sua origem seja, com certa frequência, 
atribuída à democracia norte-americana, a divisão de seu sistema representativo em distritos eleitorais, não atribui igual peso ao voto de cada cidadão ${ }^{3}$.

Já para Schumpeter (2010[1940]), a democracia se apresenta como um método de seleção de elites via eleições, e não necessariamente como um meio para se chegar a um fim, como uma representação justa, por exemplo. Ela não pode ser entendida como um valor, pois seu método pode levar a diferentes caminhos, até mesmo autoritários e antidemocráticos.

É nesse sentido que Dahl argumenta que as teorias democráticas modernas pensam a respeito dos processos de controle de lideranças, minoritária ou majoritariamente (DAHL, 2006, p. 18). No constitucionalismo moderno, decisões por maiorias qualificadas ou contramajoritárias impedem que direitos que protegem minorias sejam violados ${ }^{4}$, ainda que tais decisões também sirvam para manter o status quo. O autor concebe o poder pluralisticamente, uma vez que minorias e maiorias se alternariam ao longo do tempo e conforme as questões mais latentes a serem decididas em sociedade, fazendo da distribuição de poder um valor central de sua teoria. Ainda que trace horizontes normativos para pensarmos a autonomia da dimensão política e isolarmos cognitivamente as instituições políticas, Dahl também desenvolve sua teoria olhando para como ocorrem os processos

\footnotetext{
3 Dahl ressalta que Madison discordava da representação igual dos Estados norteamericanos no Senado, que fora atribuída a ele por defendê-la como melhor solução conciliatória durante o Conselho Constitucional, fazendo com que esse ideal fosse equivocadamente atribuído aos seus escritos. Dahl define a democracia madisoniana como um modelo teórico cuja meta política era estabelecer preceitos e controles constitucionais entre líderes e poderes, a fim de se evitar uma república tirânica. Mas um dos problemas encontrados nos escritos dos papers federalistas de Madison, seria o fato de que ele não chega a definir de forma clara, o que caracterizaria minorias e maiorias, apenas que ambas poderiam ser tirânicas. Além disso, sua preocupação com uma possível ameaça aos direitos naturais se dirigia aos direitos dos "bem nascidos e poucos" (Dahl, 1989, p. 83).

4 No Brasil, o Supremo Tribunal Federal (STF) cada vez mais tem assumido essa função, mesmo se tratando de um colegiado não eleito pelo voto popular.
} 
democráticos na prática. Ou seja, para aquilo que ele denominou poliarquia: a democracia realmente existente.

Se valendo de exemplos históricos de votações norte-americanas no Senado, no Supremo Tribunal e de resultados de eleições presidenciais norte-americanas, Dahl (1989[1956]) argumenta que, por mais que ideais democráticos como a defesa da representação igual tenham permanecido como inerentes à democracia representativa, maiorias não governam e o medo de Madison de que uma tirania da maioria pudesse colocar em risco a república, é algo que, naquela época, seria desprovido de sentido empírico e só poderia ser afirmado por inferência lógica.

Considerando esses problemas, o que o modelo poliárquico pretende é trazer subsídios para que se possa, olhando mais para variáveis sociais que constitucionais, "construir uma teoria satisfatória sobre a igualdade política" existente nas democracias reais. Dahl estabelece oito condições ideais ${ }^{5}$ que não são atingidas por nenhum de seus três modelos, mas a partir das quais é possível avaliar o grau de consenso sobre a aplicação dos procedimentos democráticos, tendo em vista a inclusão no processo decisório, via sufrágio universal, e a extensão da igualdade política. Para o que se pretende neste trabalho, a separação analítica proposta por Dahl é importante, pois se preocupa com o fato de que a distribuição desigual de "renda, riqueza, status e controle sobre os recursos organizacionais", afeta sobremaneira a

\footnotetext{
${ }^{5}$ As condições se aplicam desde o estágio pré-eleitoral até o período pós-eleitoral e, de forma a garantir a aplicação da regra da maioria, estabelecem que: 1) Todos os membros da organização política manifestam suas preferências e votam; 2) O peso do voto de cada indivíduo possui igual valor; 3) Vence a alternativa mais votada; 4) Os membros podem inserir alternativas às que foram apresentadas; 5) As informações sobre as alternativas devem ser igualmente distribuídas entre os membros; 6) Líderes ou políticas mais votadas substituem as menos votadas; 7) O que os eleitos ordenarem deverá ser executado; e, 8) Entre as eleições, que as decisões tomadas sejam subordinadas às ou executem decisões tomadas durante a fase eleitoral ou que, se forem novas decisões, tenham em vista as sete condições anteriores, ou as duas coisas (DAHL,1989, pp. 70-4).
} 
participação política nos sistemas representativos considerados democráticos (DAHL, 1989, pp. 82-4)

Dahl apresenta uma argumentação consequencialista, ou seja, no sentido de que não há como escolhermos uma concepção de democracia como mais desejável, uma vez que não é possível saber a que consequências ela levará. Logo, para o autor, a democracia seria um valor dependente dos resultados que produz. Guardadas as devidas diferenças, sobretudo em relação ao entendimento da democracia apenas como método, é nesse sentido que a maioria da(o)s autora(e)s que advogam por reformas em arranjos representativos como meio para se atingir um determinado fim que seria, por assim dizer, "mais democrático", desenvolvem seus argumentos.

\section{Democracia, princípios e critérios para uma representação mais justa}

Partindo do pressuposto de que uma democracia justa não deve violar princípios e direitos, podemos argumentar que ela deve ser compatível com critérios e normas que visem uma representação justa. Logo, ela não deve ser vista apenas como um ideal ou concebida a partir de uma visão minimalista de poder ou de seleção de elites quando, a despeito de possuírem direitos formais, nem todos os cidadãos possuem o direito de exercer plenamente suas liberdades civis e políticas. Ter o direito de impactar o lhe concerne no plano individual, portanto, diz respeito àquilo que está no plano da igualdade política.

Ao pensarmos sobre que tipo de igualdade política é desejável, devemos ter em mente o que queremos aperfeiçoar quando falamos de procedimentos democráticos que visam uma representação política justa. Além de igualdades básicas como de recursos e bens primários, um modelo representativo inclusivo precisa contemplar com mais cuidado as questões ligadas à formação da agenda, ao acesso aos meios de comunicação de massa e às esferas de produção de interesses coletivos (MIGUEL, 2003, p. 123). 
A teoria democrática transita entre o plano dos valores e o da explicação. Conforme argumentam Sen e Nussbaum (1993), a democracia possui tanto um valor intrínseco quanto instrumental, pois está diretamente relacionada ao poder de agência dos indivíduos e sua capacidade de escolha genuína sobre questões que lhes afetam. Além da necessidade de os indivíduos serem capazes de formar suas preferências de maneira autônoma, "a construção de uma ordem democrática, qualquer que seja ela, coloca uma série de desafios - a relação entre as preferências individuais e uma hipotética "vontade coletiva", ou seja, o desafio de conciliar a expressão de diferenças e interesses individuais com a manutenção de "uma unidade mínima" (MIGUEL, 2005, p. 26).

A democracia eleitoral, por seu turno, pressupõe uma concepção de liberdade política que engloba o direito às liberdades de consciência, expressão e associação. Uma concepção de justiça, por sua vez, é uma concepção democrática. Mas esses três tipos de liberdade careceriam de uma concepção de igualdade (quer seja material, de bemestar, relativa aos direitos humanos ou política), para que sirvam para avaliarmos a representação democrática conforme critérios de justiça.

Ronald Dworkin (1987) e Charles Beitz (1989), são autores que pensam a democracia tendo em vista esses critérios - considerando que "representa" quem possui cargo eletivo. Dworkin, inserido na corrente liberal-igualitária inaugurada pelos escritos de Rawls (1971):-iob, possui uma concepção dependente de democracia, uma vez que, para que seja justa, ela precisa garantir igual acesso ao debate político e expressar o valor da igualdade humana fundamental. Assim, a democracia precisa ser condizente com o que o autor denomina princípio da igualdade de consideração.

Beitz, assim como Dowrkin, analisa a democracia de forma dependente de uma concepção de justiça e de uma concepção de bemestar que servem para avaliar até que ponto princípios ideais ou direitos formais se traduzem ou não em resultados democráticos justos ou, mais especificamente, em direitos sociais e políticos efetivos. $\mathrm{O}$ autor constata 
a dificuldade de transportarmos e afirmarmos valores universais quando olhamos para as instituições políticas realmente existentes, considerando que, frequentemente, e em termos rawlsianos, elas não expressam o valor equitativo das liberdades políticas dos cidadãos. Nesse sentido, podemos afirmar que Dworkin, Beitz e Manin compartilham a ideia de que o próprio conceito de representação política traz consigo um significado de exclusão.

A dificuldade de transposição de princípios e valores para o plano concreto das instituições democráticas liberais, em meio a crescentes reivindicações ancoradas na valorização de identidades cada vez mais plurais, revela o quanto "a própria noção de representação se baseia em expectativas inconciliáveis". Como argumenta Limongi, "queremos que os representantes sejam os mais capazes possíveis, mas ao mesmo tempo queremos que eles defendam os nossos interesses, que sejam, portanto, a um só tempo, diferentes e iguais" (LIMONGI, 2015, p. 24).

Tendo em vista a dificuldade de se atingir um modelo de representação que busque reparar as desigualdades distributivas e de recursos - como a ausência de igual acesso à saúde, educação e também ao poder político, as democracias contemporâneas ainda estariam longe de serem representativas. Além disso, o que se configura como crise de representação, para além da crescente ausência de identificação entre representantes e representados e da não efetivação de direitos formais ancorados nos princípios de liberdade (em seu sentido positivo) e igualdade política (no sentido de autogoverno individual e coletivo), seria sempre relacionado a mudanças de arranjos institucionais específicos ao longo do tempo. Ainda que por si só não resolvam a baixa representação política das mulheres, como será visto a seguir, as cotas eleitorais de gênero foram adotadas há quase três décadas no Brasil como parte do objetivo de dirimir esses problemas. 


\section{Representação política de mulheres no Brasil: sistema eleitoral e ações afirmativas como medidas de justiça}

Desde a década de 90, diversos projetos de lei passaram a tramitar no Congresso Nacional com o objetivo de diminuir a subrepresentação de mulheres na política brasileira. Algumas dessas propostas versam sobre o sistema de financiamento de campanha, ao passo que outras, discorrem sobre como incluir e aumentar a representação descritiva e proporcional de grupos ainda muito pouco representados na política.

As análises mais empíricas sobre representação feminina no Brasil revelam não só que estamos muito atrás em termos de maior inclusão e participação das mulheres na vida política, como que há uma elevada disparidade de gênero tanto entre os indivíduos que se candidatam, quanto entre os que de fato são eleitos. Tal problema não seria exclusivo do país, dado que

na maior parte dos sistemas políticos, as mulheres ocupam uma pequena proporção dos cargos públicos eleitos, bem como estão relativamente pouco presentes nas posições de poder e influência na vida pública e privada de modo geral. Grupos culturais minoritários e aqueles situados em posições raciais desvalorizadas também costumam carecer de voz política efetiva (YOUNG, 2006, p. 169).

No Brasil, a legislação sobre cotas destinadas a reserva de vagas por gênero foi adotada pela primeira vez em 1995, estabelecendo que $20 \%$ dos candidatos a cargos eletivos locais deveriam ser mulheres ${ }^{6}$. Dois anos mais tarde, a legislação ampliaria essa cota, estabelecendo que os partidos ou coalizões deveriam obedecer a um mínimo de 30\% e um máximo 70\% de cada sexo para as eleições em qualquer nível. Em 2009, uma Proposta de Emenda Constitucional (PEC), passou a exigir que os partidos políticos destinassem ao menos $10 \%$ do horário da propaganda eleitoral gratuita e $5 \%$ dos recursos públicos de campanha para

6 O que passou a valer apenas nas eleições de 1998. 
promover a inclusão das mulheres na política. Os partidos que não cumprissem tal determinação, sofreriam uma penalidade adicional de $12,5 \%$ do valor do fundo partidário, para serem direcionados ao mesmo fim. O Tribunal Superior Eleitoral (TSE), por sua vez, ficaria encarregado de destinar ao menos 5 minutos em programas de rádio e televisão com abordagens que promovessem uma conscientização e incentivassem uma maior participação política de mulheres.

Desde a adoção dessas primeiras regras até as proposições mais recentes de mudanças, tem-se argumentado que existem inúmeros fatores condicionantes e intervenientes sobre a inclusão das mulheres nas esferas de poder e que interferem na eficácia das cotas, ou seja, no aumento da representação política de mulheres. Dentre eles, se encontram o sistema eleitoral e o tipo de lista adotado por cada país (aberta ou fechada), além da cultura política enraizada na sociedade e refletida nas instituições políticas (NORRIS; INGLEHART, 2003; ARAÚJO, 2016).

Fernando Limongi aponta que o período pós redemocratização no Brasil trouxe consigo a ideia de que os problemas referentes a representação política, em uma sociedade com movimentos sociais efervescentes, estariam na "matriz institucional brasileira". Ou seja, na junção do presidencialismo com representação proporcional em lista aberta que não conseguiria canalizar as demandas, cada vez maiores (LIMONGI, 2015, p. 16,17). Posteriormente, os problemas advindos do déficit participativo de uma pluralidade de grupos sociais (mulheres, negros, indígenas, homossexuais), nas esferas de poder seriam atribuídos à "fragilidade do governo", causada por essa mesma matriz. Como se vê, "temas e instituições específicas permanecem as mesmas, mas as razões pelas quais são vistos como problemáticos mudam inteiramente" (Idem: ibidem).

Conforme argumenta Nicolau (2012), os sistemas de representação proporcional, tal como o brasileiro, surgem a partir de críticas feitas por Thomas Hare e Stuart Mill aos sistemas majoritários, que acabariam por privilegiar interesses de comunidades ou partidos 
políticos dispostos geograficamente, em detrimento das representações individuais e das minorias. Inicialmente, as propostas alternativas deste novo sistema foram o voto único transferível e o voto de lista, de forma a garantir que as principais opiniões da sociedade estivessem representadas no legislativo e que cada partido fosse representado conforme os votos recebidos, respectivamente.

O aumento das possibilidades de escolha pelo eleitor, baseado nestes modelos onde há o cálculo de uma cota, foi posteriormente aperfeiçoado por Victor D'Hont, a fim de que a distribuição das cadeiras estivesse pautada na votação obtida por cada partido. Este, por sua vez, possui centralidade na representação proporcional de lista, onde cada um apresenta seus candidatos, podendo o eleitor tanto escolher uma delas, quanto votar em um ou mais nomes. A divisão dos distritos eleitorais, por sua vez, influi diretamente na eleição, já que, quanto maior o número de cadeiras, maior a probabilidade de um partido pequeno estar representado. Isto reduz a fragmentação partidária e eleva a proporcionalidade da distribuição de cadeiras, ainda que se estabeleça a crítica do prejuízo à governabilidade.

Segundo Nicolau, neste sistema utilizam-se os métodos de sobras e divisores. O primeiro se refere a uma cota (Hare) préestabelecida a ser atingida por cada partido - ou que, posteriormente, se chegue próximo a ela - para que se ocupe as cadeiras. No segundo, os votos dos partidos são divididos por um número de série, onde os que obtêm as maiores médias ocupam as cadeiras. Isto pode ser feito de forma sequencial (fórmula D'Hont), geralmente favorecendo os maiores partidos, ou pelo uso de divisores ímpares (método de Sainte-Laguë). Os sistemas pautados nos métodos de sobras e divisores exemplificam o fato de que "quase nenhuma lei eleitoral aplica o princípio de "uma pessoa um voto" na correspondência entre o número de votos e o número de assentos" (CASTELLS, 2018, p. 12).

Além da influência da fórmula eleitoral, há ainda a cláusula de barreira, cujo objetivo é evitar a dispersão partidária no legislativo, estabelecendo uma base mínima de voto e restringindo o acesso dos 
pequenos partidos. Por outro lado, existe a possibilidade de se fazer alianças partidárias, via coligações, aumentando as chances destes pequenos partidos atingirem a representação.

Já o ordenamento dos candidatos nestas listas pode ser feito de forma fechada, aberta ou flexível. Na primeira, a ordem dos candidatos é previamente decidida pelos partidos e o eleitor vota em um deles. $\mathrm{Na}$ segunda, os eleitores votam em nomes, acirrando a disputa eleitoral. $\mathrm{Na}$ lista flexível, os partidos ordenam os candidatos e os eleitores podem votar no partido ou discordando da disposição da lista, votar em nomes específicos dela. Por fim, há ainda um sistema mais complexo que é o voto único transferível (STV), onde eleitores podem votar em candidatas(os) de mais de um partido e reordená-las(os) conforme sua preferência. Assim sendo, a transferência de voto é muito mais específica que no sistema de lista aberta, utilizado no Brasil (NICOLAU, 2012). Nesse sentido, Clara Araújo argumenta que "quando aplicadas, as cotas são bem mais eficazes nos sistemas de listas fechadas, e bem menos ou nada eficazes nos sistemas de listas abertas" (ARAÚJO, 2016, p. e40).

Um dos últimos Projetos de Lei levados ao plenário e ainda em tramitação, é a Proposta de Emenda à Constituição (PEC) 23/2015. Seu texto original se baseava na defesa da paridade de gênero, mas foi alterado pela senadora Simone Tebet (PMDB-MS), de forma que a proposição reserve $30 \%$ das vagas para mulheres, tanto na Câmara dos Deputados, Senado Federal, assembleias legislativas, quanto nas câmaras de vereadores. Mais recente ainda, é o projeto de lei da deputada Caroline de Toni (PSL-SC), apresentado em agosto de 2020, em plena pandemia de Covid-19, com o intuito de extinguir a cota eleitoral para reserva de vagas por cada partido para mulheres e em eleições proporcionais vigente no país - mínimo 30\% e máximo 70\%, válido para Câmara dos Deputados, para a Câmara Legislativa do Distrito Federal (CLDF), Assembleias legislativas e Câmaras municipais. Em suas palavras: 
Para além de toda carga ideológica que cerca o tema igualdade de gênero, o fato é que, estritamente do ponto de vista prático, desde que essa famigerada cota foi inserida na legislação eleitoral pela Lei $\mathrm{n}^{\circ}$ $12.034 / 2009$, os partidos políticos têm enfrentado uma série de problemas com aplicação da referida norma. Conquanto seja louvável o incentivo à participação feminina na política, é inegável que infelizmente apenas uma parcela muito pequena das mulheres de fato, se interessa por desenvolver atividade político-partidária ${ }^{7}$.

Por um lado, a deputada parece ignorar as diversas causas que levam a um suposto "desinteresse" de mulheres por política, sendo uma delas, o próprio déficit representativo nas instituições. Uma vez que os partidos tendem a preferir candidatos que já foram eleitos em algum pleito anterior, ele se soma à ausência de incentivos das próprias legendas partidárias, de programas qualificados que visem a formação política para mulheres candidatas, dentre outros fatores ligados à própria dinâmica partidária - que requer uma base sólida de apoio para que as mulheres abdiquem, por exemplo, de um trabalho remunerado fora dessa arena e se dediquem a todos os compromissos de uma campanha cujo resultado pode ter doses altas de incerteza. De outro, o argumento parece ser tautológico: não vamos enfrentar problemas políticos e sociais, pois as tentativas de mudança resultam em problemas políticos e sociais. A autora do projeto se esquece ainda que, além de muito provavelmente ter sido beneficiada pela legislação eleitoral de cotas, seu próprio partido, segundo inquérito instaurado pela Polícia Federal ${ }^{8}$, em vez de se preocupar com os subsídios para candidaturas mulheres e cumprimento da legislação eleitoral vigente, estava mais empenhado em burlá-la, angariando parte do fundo eleitoral por meio de candidaturas laranja.

\footnotetext{
7 Projeto completo disponível em: [Link]. Acessado em 22 ago. 2020.

8 FOLHA DE SÃO PAULO. São Paulo: Grupo Folha [2019]. Disponível em: https:// www1.folha.uol.com.br/poder/2019/11/policia-federal-indicia-bivar-e-trescandidatas-laranjas-do-psl-em-pernambuco.shtml. Acesso em: 10 set. 2020.
} 
Ao analisarmos essas proposições, sobretudo as que partem de mulheres, é preciso considerar que a representação política envolve ideias, interesses e perspectivas sociais que podem ser conflitantes. Tampouco podemos deixar de lado a crítica já feita por teóricas feministas sobre a categoria homogeneizante de "mulher", pressupondo a universalização de questões e interesses que partem de contextos e vivências muito particulares a depender da raça, classe, etnia, sexualidade e que, portanto, não podem ser entendidos sob uma base biológica (ANTHIAS; YUVAL-DAVIS, 1993). Como argumenta Young, ao tentar rebater a crítica de que sua teoria da representação cairia em um essencialismo identitário, a autora advoga que mecanismos de representação especial como as cotas, não devem ser pensados como permanentes uma vez que, em suas palavras,

em qualquer forma que assuma, a representação de grupos não deve ser concebida somente por referência a atributos compartilhados por pessoas, assim como não consiste na manifestação de algum conjunto de opiniões, interesses ou experiências que todos os membros do grupo compartilhem (YOUNG, 2006, p. 171).

Outro aspecto da disparidade de gênero se encontra na cultura política do país. Atrelada a papeis social e historicamente fixados no passado, ela seria responsável por reforçar a crença de que o lugar da mulher residiria na esfera privada das relações sociais, ao passo que o do homem seria o da esfera pública (PATEMAN, 1988; OKIN, 2008). Se, por um lado, a reflexão aqui suscitada refere-se à representação daquelas e daqueles indivíduos que são de fato eleitas(os) pelo voto popular e cujo processo é mediado por ações afirmativas de gênero, de outro, não deixa de ser sintomático dos valores e da cultura política do país, assim como de seu momento político atual, que dos 22 cargos ministeriais do governo do Presidente Jair Bolsonaro, apenas 2 sejam 
ocupados por mulheres ${ }^{9}$ - diga-se de passagem, mulheres brancas e de posições conservadoras em pautas de direitos de minorias ou ligadas aos costumes sociais.

Ademais, como parte dessa mesma cultura, a divisão sexual do trabalho seria um outro fator analisado por teóricas feministas da representação (PHILLIPS, 2001; YOUNG, 2006), que limitariam as possibilidades de escolha autônoma das mulheres, dificultando uma participação mais ativa delas nos assuntos públicos e nos espaços de poder. As autoras advogam um tipo de representação descritiva, em outras palavras, ações afirmativas que baseiam na valorização positiva da diferença, de modo que reformas em arranjos institucionais possibilitem uma maior participação de minorias políticas como as mulheres.

Se as abordarmos sob a ótica do debate entre federalistas e antifederalistas, podemos situar as teorias feministas da representação como mais alinhadas à corrente antifederalista. Como bem nos mostra Manin, “os federalistas possuíam uma concepção descritiva de representação" (MANIN, 2015, p. 204), mas não defendiam que todas as classes estivessem representadas na Assembleia. Os antifederalistas, por seu turno, estavam preocupados com a proporcionalidade entre eleitos e eleitores, uma vez que estes últimos poderiam não estar devidamente representados em grandes distritos eleitorais. Embora tenham sido negligenciados no debate norte-americano do século XVIII, os argumentos antifederalistas possuíam um "ideal de similaridade", pautado na "conciliação quase perfeita entre divisão do trabalho e o princípio democrático da igualdade” (MANIN, 2015, p. 223).

Na América Latina, o Brasil figura como um dos países com maior discrepância em termos de igualdade de gênero na representação política legislativa. Dados mais recentes da pesquisa “Estatísticas de

9 Ministra Tereza Cristina, responsável pela pasta da Agricultura, Pecuária e Abastecimento do Brasil e Ministra Damares Alves, responsável pela pasta da Família, Mulher e Direitos Humanos. 
gênero - Indicadores sociais das mulheres no Brasil"10, realizada pelo Instituto Brasileiro de Geografia e Estatística (IBGE), apontam que o país ocuparia a $152^{\circ}$ posição no ranking mundial dos Estados que apresentam uma maior representação feminina. Em 2014, 28 partidos políticos obtiveram assentos na Câmara, mas somente 17 elegeram mulheres, totalizando 51 deputadas federais eleitas. No Senado, apenas 12 mulheres figuravam entre os 81 senadores eleitos. De uma maneira geral, seus perfis demonstram que são mulheres de escolaridade e idade mais elevadas, além de longa participação política e eleições pregressas para cargos de deputado estadual, vereador e prefeituras (ARAÚJO, 2016). Após a eleição de 2018, que parece ter caminhado no sentido de mudar um pouco esta última tendência, das 513 cadeiras ocupadas na Câmara dos Deputados, apenas 77 delas foram preenchidas por mulheres, o que representa $15 \%$ do total de eleitos para o cargo de deputado federal 11 , um aumento de apenas 4,5\% se comparado à eleição anterior para cargos majoritários.

Clara Araújo argumenta que não basta apenas regulamentarmos o acesso aos cargos via cotas eleitorais, mas que também é preciso enrijecer o controle sobre como elas são aplicadas pelos partidos, quer seja em sistemas que trabalhem com lista aberta ou fechada. Assim,

mesmo no sistema de lista fechada, para se tornarem eficazes essas políticas de cotas necessitam de três requisitos: legislações mais duras e mais claras quanto a obrigações dos partidos políticos em cumprirem os percentuais mínimos; definição de alternâncias na ordem de apresentação dos nomes nos sistemas de lista fechada, de modo que os nomes das mulheres não fiquem na base das listas, ou seja, não fiquem entre aqueles de quem não se espera

\footnotetext{
10 Cf. IBGE. Disponível em https://www.ibge.gov.br/estatisticasnovoportal/multidominio/genero/20163-estatisticas-de-genero-indicadores-sociaisdas-mulheres-no-brasil.html?=\&t=o-que-e. Acessado em 16 mar. 2019.

11 É possível acessar esses e outros dados mais recentes e comparativos sobre representação feminina e políticas de gênero em diversos países, no site do IDEA (Institut of Democracy and Electoral assistence), vinculado à Inter-parlamentary Union e à Universidade de Estocolmo.

Cf. <https://www.idea.int/data-tools/data/gender-quotas/country-view/68/35>.
} 
sucesso eleitoral; e legislações mais punitivas nos casos de não cumprimento de alguns dos requisitos anteriores (ARAÚJO, 2016, p. e40).

Quer seja na argumentação de que o problema da baixa representação de mulheres na política reside no sistema proporcional com voto em lista aberta, ou nas que se baseiam em questões socioculturais que influenciam não só as escolhas intrapartidárias sobre os candidatos e reduzem as chances de vermos mais mulheres nas instâncias de poder, as democracias liberais têm demonstrado certa dificuldade em canalizar novas demandas representativas de grupos minoritários. Como analisa Castells, "a democracia se constrói em torno das relações de poder social que a fundaram e vai se adaptando à evolução dessas relações, mas privilegiando o poder que já está cristalizado nas instituições" (CASTELLS, 2018, p. 12).

Interesses e preferências políticas necessitam ser entendidos como algo sempre em processo de formação, não como algo dado de antemão. Um dos problemas centrais das democracias contemporâneas seria o de como transportar escolhas ou vontades individuais para o plano da escolha social e, ao mesmo tempo fazer com que a liberdade e igualdade formais se transformem, em liberdade e igualdade efetivas. A partir disso, é possível afirmar que ter mais mulheres como representantes na política contribui para uma mudança sobre visões que as engessam em papéis sociais específicos, em termos simbólicos, podendo funcionar como um estímulo a sua participação social e política.

Em termos mais substantivos também permite que sua atuação impacte políticas públicas que dizem respeito a vários de seus direitos ou questões que lhes são concernentes e que poderiam, pelo próprio jogo político, estar sendo debatidas exclusivamente por homens: violências contra a mulher (pauta esta, que seria menos controversa entre candidatas de diferentes espectros ideológicos - algo evidenciado na aprovação da Lei Maria da Penha e Lei contra o Feminicídio no 
Brasil) e, é claro, sua ascensão em termos econômicos, considerando a equidade salarial que os cargos eletivos asseguram.

Como argumenta Beitz, na prática, os procedimentos democráticos são complexos e não simplesmente traduzem preferências, mas também as criam. Justamente por isso, é preciso que haja oportunidades institucionais concretas, conectadas a uma rede de recursos que visem diminuir desigualdades distributivas e de status, para que o acesso igual ao poder político, de fato $\_$seja viabilizado.

\section{Conclusão}

Em tempos de retrocessos democráticos e, tendo em vista mulheres que defendem pautas conservadoras ligadas aos direitos sexuais e reprodutivos na esfera institucional brasileira, o presente trabalho buscou abordar as potencialidades e os limites da inclusão de grupos minoritários nas instâncias de poder político, que, por vezes, entra em conflito com o conteúdo substantivo da representação. A despeito das divergências entre mulheres eleitas, principalmente àquelas ligadas a esses direitos, argumento que reformas institucionais que busquem diminuir desigualdades de gênero na representação política devem ser defendidas não só em termos de igualdade política, mas também como uma questão de justiça.

Tendo em vista as questões aqui abordadas, podemos afirmar que desigualdades na esfera privada da vida das mulheres, resguardadas as diferenças e impactos de raça, etnia e classe que as colocam em posições diferentes no mercado de trabalho e, muitas vezes em situação de desvantagem em relação a mulheres brancas - que figuram como a grande maioria dentre as mulheres eleitas -, diminuem seu autogoverno individual. Em sociedades altamente desiguais, reformas que visam incluir grupos historicamente alijados das instituições políticas e das esferas de poder, aumentam substantivamente a qualidade da democracia, na medida em que são compatíveis com critérios de justiça e de equidade política que, por seu 
turno, favorecem o autogoverno coletivo. Nesse sentido, elas podem ser defendidas em um plano ontológico e de forma consequencialista, resgatando o sentido da argumentação de teóricos da democracia, pois aumentam em algum grau a liberdade política das mulheres que, com maior liberdade para se candidatarem, se expressarem publicamente e se dedicarem à vida política, - incluindo aqui os subsídios necessários para isso, sobretudo suporte e incentivos que devem ser dados pelos partidos políticos -, contribuem com a valorização do autogoverno coletivo desse grupo social.

Por outro lado, em termos principiológicos e de valores, podemos argumentar que elas são desejáveis mesmo que as consequências de sua adoção não sejam necessariamente ter mais mulheres que pensam como nós em questões diversas ou que irão defender os mesmos interesses e ideais que temos. Apesar de haver diferenças importantes de trajetórias políticas entre partidos políticos de direita e de esquerda, como apresentam as pesquisas realizadas por Resende e Epitácio (2017), a baixa representação das mulheres no Brasil não é algo que diz respeito meramente ao espectro ideológico, dado que sua ausência no legislativo brasileiro pode ser observada tanto em partidos mais alinhados à esquerda, quanto naqueles considerados de centro e de direita. Ter mais mulheres na política, portanto, pode ser defendido como parte de um princípio de justiça que visa alcançar maior equidade da representação entre os indivíduos, em regimes democráticos. Logo, uma participação política mais equitativa seria desejável e defensável em termos normativos e morais, independentemente do conteúdo advindo de uma determinada proposição política.

É importante ressaltar ainda que, por mais que valores ideais como os de liberdade e igualdade política sejam utilizados como gradientes da democracia, tê-los em menor grau não faz, necessariamente, com que um regime político deixe de ser democrático. Como nos lembram Beitz e Dworkin, o que precisamos sempre levar em conta ao nos debruçarmos sobre as pesquisas de cunho teórico e 
empírico que versam sobre a representação política de uma maneira geral, é sobre que tipo de igualdade estamos falando. Neste trabalho, abordei reformas institucionais tomando como exemplo a adoção de cotas para o estabelecimento de uma representação mais equitativa, pautada pela igualdade política de gênero. Desigualdades distributivas de recursos e a disparidade na relação entre poderes públicos e privados são questões que dizem respeito ao campo da justiça e, quando somadas à cultura política de um país, afetam o funcionamento das democracias constitucionais contemporâneas e têm um relevante impacto na representação política de mulheres.

\section{Referências}

ANTHIAS, F.; YUVAL-DAVIS, N. Racialized Boundaries. Race, nation, gender, colour and class and the anti-racist struggle. London: Routledge, 1993.

ARAÚJO, Clara. Valores e desigualdade de gênero: mediações entre participação política e representação democrática. Civitas - Revista de Ciências Sociais, v. 16, n. 2, 2016.

BEITZ, Charles. Political equality. Princeton: Princeton University Press, 1989.

CASTELLS, Manuel. Ruptura: a crise da democracia liberal. Tradução de Joana Angélica D'Avila Melo. 1. ed. Rio de Janeiro: Zahar, 2018.

DAHL, Robert. A preface to democratic theory. Expanded edition. Chicago: The University of Chicago Press, 2006.

DWORKIN, Ronald. What is equality? Part 4: Political equality. University of San Francisco Law Review, v. 22, n. 1, p. 1-30, 1987.

DWORKIN, Ronald. La virtud soberana: la teoria y la practica de la igualdad. Editora: Paidós, Barcelona, 1993.

LIMONGI, Fernando. Reforma Política: o longo debate. Revista Parlamento e Sociedade, Dossiê Reforma Política - Primeira parte, v. 3, n. 4, 2015.

MANIN, Bernard. As metamorfoses do governo representativo. Revista 
Brasileira de Ciências Sociais, v. 29, p. 5-34, 1995.

DWORKIN, Ronald. O princípio da distinção. Revista Brasileira de Ciência Política, Brasília, n. 4, p. 187-226, jul./dez. 2010.

MANIN, Bernard; PRZEWORSKI, Adam; STOKES, Susan. Eleições e Representação. Lua Nova, São Paulo, n. 67, p. 105-138, 2006.

MIGUEL, Luis Felipe. Representação Política em 3-D. Elementos para uma teoria ampliada da representação política. Revista Brasileira de Ciências Sociais, v. 18, n. 51, 2003.

MIGUEL, Luis Felipe. Impasses da accountability: dilemas e alternativas da representação política. Rev. Sociol. Polit., n. 25, p. 25-38, 2005.

NICOLAU, Jairo Marconi. Sistemas Eleitorais. 6. ed. Rio de Janeiro: Editora FGV, 2012.

NORRIS, P.; INGLEHART, R. Gender Equality and Cultural Change around the World. Cambridge, Mass: Cambridge University, 2003.

PATEMAN, C. The Sexual Contract. Cambridge: Polity Press, 1988.

PHILLIPS, Anne. The politics of presence. Oxford: Oxford University Press, 1998.

PHILLIPS, Anne. De uma política de ideias a uma política de presença? Revista Estudos Feministas, v. 9, n. 1, p. 268-90, 2001.

RAWLS, J. A Theory of Justice. Cambridge (Ma): Harvard University, 1971.

RESENDE, Roberta Carnelos; EPITÁCIO, Sara. Mulheres à esquerda e à direita: carreiras políticas e partidos políticos. Mediações - Revista de Ciências Sociais, v. 22, n. 1, 2017.

SCHUMPETER, Joseph A. Capitalismo, socialismo e democracia. São Paulo: Editora da Unesp, 2017 [1940].

SEN, Amartya; NUSSBAUM, Martha (Org.). The Quality of Life. Oxford: Clarendon Press, 1993.

YOUNG, Iris. Representação política, identidade e minorias. Lua Nova, São Paulo, n. 67, 2006. 